\title{
Primary anorectal malignant melanoma: a rare but aggressive tumor: report of a case
}

\author{
Dominique Buissin', Alenka Sterle ${ }^{1}$, Peter Schmiegelow ${ }^{1}$, Dirk Wassenberg ${ }^{2}$ and Peter C Ambe ${ }^{2,3^{*}}$
}

\begin{abstract}
This report presents a case of primary anorectal melanoma. A 63-year-old male presented with blood in stool. Rectal digital examination and proctoscopy revealed a mass in the anorectal junction. Transanal polypectomy was performed. Histopathology and immunohistochemistry with Melan A showed a malignant anorectal melanoma with positive resection margins. Abdomino-perineal rectum resection was performed after excluding distant metastasis. Four month later, the patient was readmitted with metastases to the liver and to the gastric mucosa. Best supportive care was initiated. This case report demonstrates the aggressive nature of this rare tumor and appeals for a less aggressive management while maintaining the quality of life.
\end{abstract}

Keywords: Anorectal melanoma, Transanal polypectomy, Melan A, Abdominoperineal rectum resection, Wide local resection

\section{Background}

Primary anorectal malignant melanoma is an extremely rare malignancy that is thought to arise from melanocytes in the mucosa around the anorectal junction. AMM is associated with a relatively poor prognosis, and surgical resection is the only curative treatment option. This case demonstrates the aggressive nature of this rare entity.

\section{Case presentation}

A 63-year-old man presented with a history of blood in the stool. Rectal examination revealed a mass in the lower rectum. A broad-based rectal polyp about $6 \mathrm{~cm}$ from the anal verge was seen on proctoscopy, and biopsies were taken (Figure 1). Histopathology showed a hyperplastic polyp. A transanal polypectomy was performed after colonoscopy. Histopathology diagnosed a malignant melanoma (Figure 2) with positive stains for melan A on immunohistochemistry (Figure 3), with positive resection margins (pT4bR1). Other primary sites and distant metastases were excluded. The patient was managed with abdominoperineal resection (APR),

\footnotetext{
* Correspondence: peter.ambe@helios-kliniken.de

${ }^{2}$ Department of General, Visceral and Thoracic Surgery, St. Remigius Hospital

Opladen, An St. Remigius 26, 51379 Leverkusen, Germany

${ }^{3}$ Helios Klinikum Wuppertal, Department of Surgery II, Witten - Herdecke

University, Heusner Str. 40, 42283 Wuppertal, Germany

Full list of author information is available at the end of the article
}

following the consensus of the interdisciplinary tumor board. Surgery and recovery were uneventful. The final tumor stage was pT4bNo (0/15) cM0pR0, stage IIC (UICC). Four months later, the patient was readmitted with tenderness in the right upper quadrant. Ultrasound demonstrated multiple metastatic lesions in the liver (Figure 4). Endoscopy revealed pigmented lesions in the gastric mucosa (Figure 5); Histopathology confirmed metastasis of a malignant melanoma. Best supportive care was initiated.

\section{Discussion}

First reported by Moore DW in 1857 [1], AMM is an extremely rare malignancy that is thought to arise from melanocytes in the mucosa around the anorectal junction. AMM constitutes about $0.05 \%$ of all anorectal malignancies $[2,3]$. The rare nature of this entity is represented by the limited number of cases described in the medical literature. The largest series from a single center included 85 cases from the Memorial Sloan-Kettering Cancer Center, reported by Brady et al. in 1995 [3].

AMM is mostly seen in the sixth decade, with a female predominance [4,5], and rectal bleeding is the most common symptom. Changes in bowel movements, rectal pain, and inguinal mass may also be present. Hemorrhoids, polyps, and other malignancies are the most common differential diagnoses $[3,4]$. 


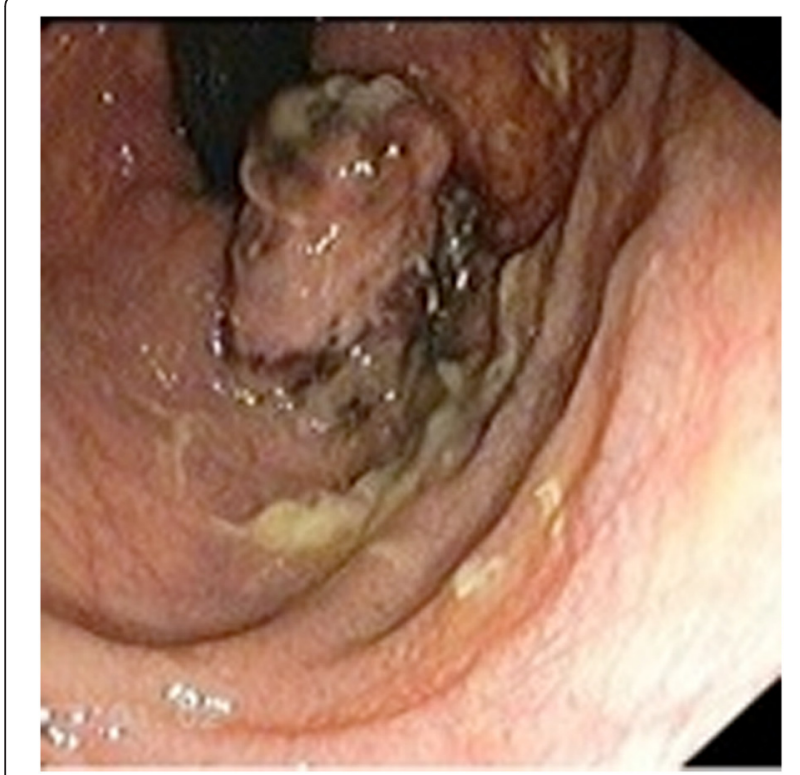

Figure 1 Endoscopic finding. Proctoscopy revealed a mass at the anorectal junction.

A mass is usually palpated on digital rectal examination. Proctoscopy usually reveals a hemorrhoid-like pigmented lesion near the anorectal junction, on which a biopsy must be performed. The histopathologic findings are similar to those of melanomas of other origins (that is. the identification of melanin and immunohistochemical staining for S100, HMD-45, and/or Melan A [6].

After the histologic diagnosis of AMM, a complete staging and search for possible distant metastases (colonoscopy, computed tomography of the abdomen and thorax, MRI of the pelvis and brain), as well as ruling out primary sites (skin and retina), are mandatory.

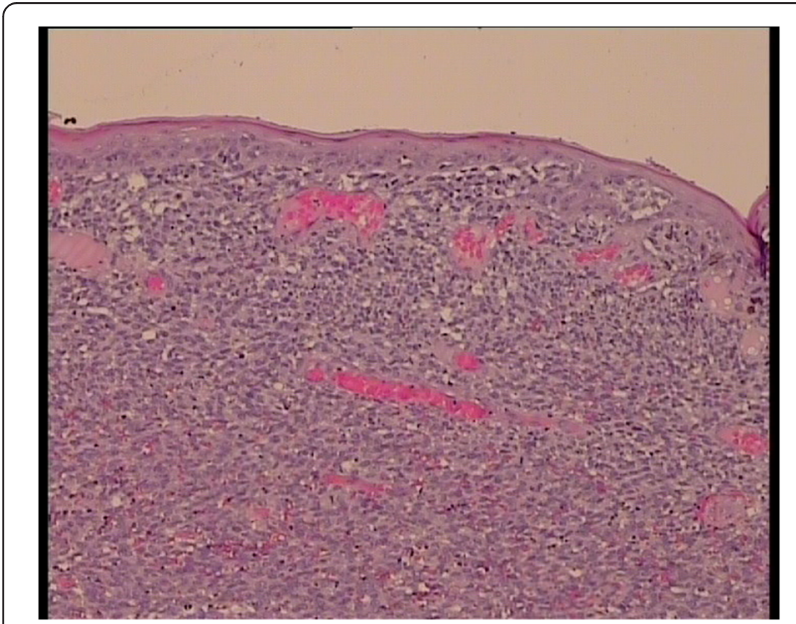

Figure 2 Hematoxylin and eosin stain. Infiltration of the mucosa through malignant cells.

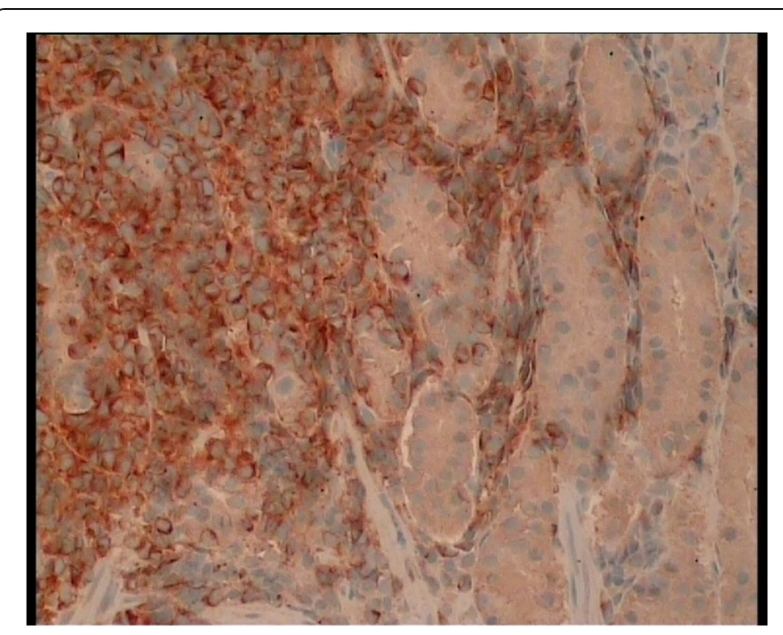

Figure 3 Immunohistochemistry. Immunohistochemical staining with Melan A confirmed the presence of melanocytes in the malignant cells.

Each patient with AMM should be discussed in an interdisciplinary board, and treatment should be individualized based on the tumor size, age, comorbidities, and absence or presence of metastases.

Surgical resection is the mainstay of treatment [5,7-9]. APR with or without bilateral inguinal lymphadenectomy and wide local excision (WLE) have been used to manage patients with AMM. APR is thought to reduce the probability of recurrence by controlling the spread to mesenteric lymph nodes and creating a larger negative resection margin $[3,4,9,10]$. However, available data suggest no significant difference in survival among patients managed with APR and WLE. Because APR is associated with high rates of morbidity and colostomy-associated decrease in the quality of life, many authors advocate WLE if negative margins

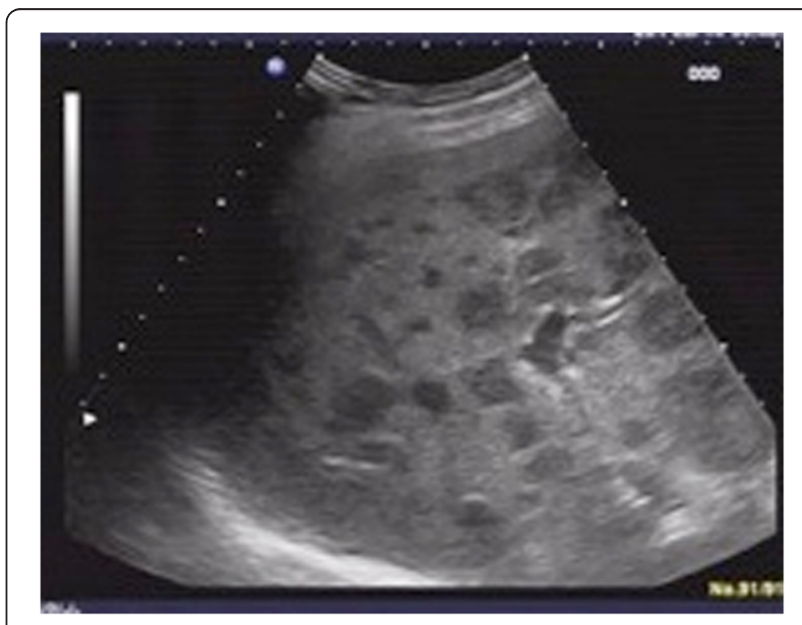

Figure 4 Liver ultrasound. Multiple liver lesions. 


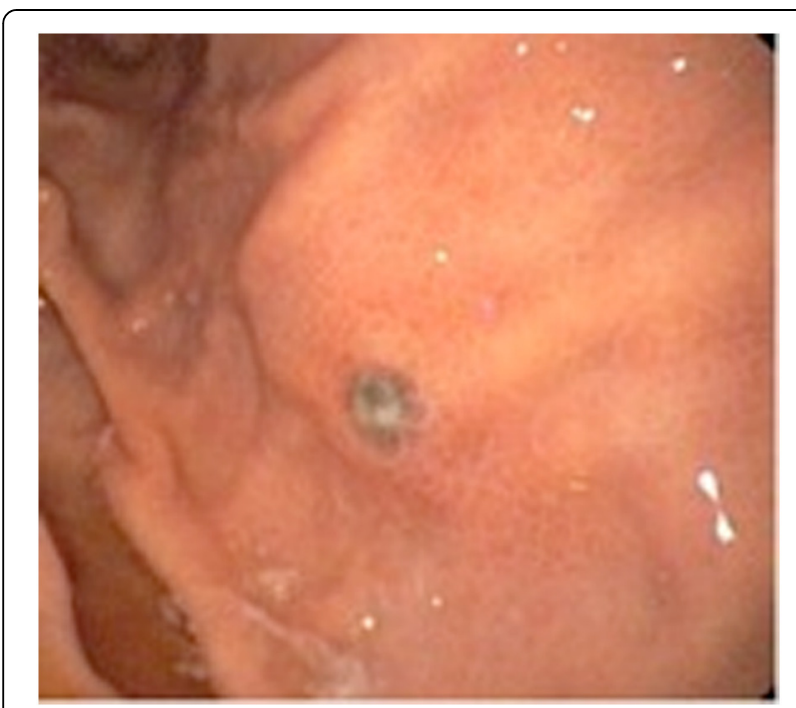

Figure 5 Upper Gl endoscopy. Pigmented lesion in the gastric mucosa stained positive for Melan A.

are achievable [7]. Chemotherapy and radiotherapy have no benefit [11].

The prognosis is poor, with overall survival rate $<20 \%$ in 5 years. Age $>60$ years and lesions $>1 \mathrm{~cm}$ in diameter have been identified as prognostic factors $[3,4,8,9]$.

\section{Conclusion}

In the case presented, AMM was diagnosed after transanal polypectomy with positive margins; thus APR was performed. Despite aggressive surgical management, disease progression was very rapid; with the development of hepatic and gastric metastases within 4 months. This case demonstrates the aggressive nature of AMM and questions the role of aggressive surgery (for example, APR) in the management of AMM. Therefore, until more evidence becomes available, the quality of life must be kept in focus when managing AMM, as is the case with WLE.

\section{Consent}

A written informed consent was obtained from the patient for the publication of this case report with the accompanying images. A copy of the consent is available for review from the Editor-in-Chief of this journal.

\section{Competing interests}

The authors declare that they have no competing interests.

\section{Authors' contributions}

Data collection: PA, DW. Performed surgical procedure: DW, PA. Literature acquisition: PA, DW. Performed histopathology: DB, AS, PS. Drafted the manuscript: PA, DW, and DB. Critically reviewed the manuscript: DB, AS, PS, DW, and PA. Final approval: DB, AS, PS, DW, and PA.

\section{Acknowledgments}

None.

\section{Author details}

'Institute of Pathology, Städtliches Klinik Solingen, Gotenstraße 1, Solingen, Germany. ${ }^{2}$ Department of General, Visceral and Thoracic Surgery, St. Remigius Hospital Opladen, An St. Remigius 26, 51379 Leverkusen, Germany. ${ }^{3}$ Helios Klinikum Wuppertal, Department of Surgery II, Witten - Herdecke University, Heusner Str. 40, 42283 Wuppertal, Germany.

Received: 26 June 2014 Accepted: 23 December 2014

Published online: 30 January 2015

\section{References}

1. Moore WD. Recurrent melanosis of the rectum after previous removal from the verge of the anus in a managed 65. Lancet. 1857;1:290-4.

2. Alexander RM, Cone LA. Malignant melanoma of the rectal ampulla: report of a case and review of the literature. Dis Colon Rectum. 1977;20:53-5.

3. Brady MS, Kavolius JP, Quan SH. Anorectal melanoma: a 64-year experience at Memorial Sloan-Kettering Cancer Center. Dis Colon Rectum. 1995;38:146-51

4. Cagir B, Whiteford MH, Topham A, Rakinic J, Fry RD. Changing epidemiology of anorectal melanoma. Dis Colon Rectum. 1999;42:1203-8.

5. Pessaux P, Pocard M, Elias D, Duvillard P, Avril MF, Zimmmermann P, et al. Surgical management of primary anorectal melanoma. Br J Surg. 2004;91:1183-7.

6. Mason JK, Helwig EB. Ano-rectal melanoma. Cancer. 1966;19:39-50.

7. Bullard KM, Tuttle TM, Rothenberger DA, Madoff RD, Baxter NN, Finn CO, et al. Surgical therapy for anorectal melanoma. J Am Coll Surg. 2003;196:206-11.

8. Ishizone S, Koide N, Karasawa F, Akita N, Muranaka F, Uhara H, et al. Surgical treatment for anorectal malignant melanoma: report of five cases and review of 79 Japanese cases. Int J Colon Dis. 2008;23:1257-62.

9. Slingluff Jr CL, Vollmer RT, Seigler HF. Anorectal melanoma: clinical characteristics and results of surgical management in twenty-four patients. Surgery. 1990;107:1-9.

10. Ross M, Pezzi C, Pezzi T, Meurer D, Hickey R, Balsch C. Patterns of failure in anorectal melanoma: a guide to surgical therapy. Arch Surg. 1990;125:313-6.

11. Malik A, Hull TL, Milsom J. Long-term survivor of anorectal melanoma: report of a case. Dis Colon Rectum. 2002;45:1412-5. discussion 1415-1417.

\section{Submit your next manuscript to BioMed Central and take full advantage of:}

- Convenient online submission

- Thorough peer review

- No space constraints or color figure charges

- Immediate publication on acceptance

- Inclusion in PubMed, CAS, Scopus and Google Scholar

- Research which is freely available for redistribution 